\title{
Two year prospective dietary survey of newly diagnosed children with diabetes aged less than 6 years
}

Suvi M Virtanen, Katriina Ylönen, Leena Räsänen, Eija Ala-Venna, Jorma Mäenpää, Hans K Åkerblom

\begin{abstract}
The food consumption of 38 children newly diagnosed with diabetes aged $<6$ years at diagnosis was assessed by 5 day food records. During the 2 year follow up, the proportion of the total energy intake made up of protein decreased from $20 \%$ to $18 \%$, that of carbohydrates from $54 \%$ to $52 \%$, and that of fat increased from $26 \%$ to $30 \%$. The energy intake from sucrose $(3 \%)$ did not change. In addition, There was a small decrease in the intake of fibre and several vitamins and minerals. One year after diagnosis, the diet of diabetic children was compared with that of 66 age, sex, and social status matched control children. More energy was derived from protein $(19 \%, v 15 \%)$ and carbohydrates $(53 \% v 50 \%)$, and less from fat $(28 \% v$ $35 \%$, especially from saturated fatty acids $(11 \% v 15 \%)$, and sucrose $(3 \% v 16 \%)$ in the diet of children with diabetes compared with that of control children. The higher intakes of several vitamins and minerals reflected the higher nutrient density of the diet of children with diabetes. Therefore, the diet of young children with diabetes met the dietary recommendations for subjects with diabetes. Only the protein content of the diet was higher than necessary.

(Arch Dis Child 2000;82:21-26)
\end{abstract}

Keywords: diet; nutrient intake; insulin dependent diabetes mellitus

Dietary recommendations for children with insulin dependent diabetes mellitus (IDDM) aim at achieving good or moderate glycaemic control, which means good coordination between insulin treatment, diet, and exercise. Other important aims are to reduce risk factors for long term complications, such as diabetic microangiopathy and cardiovascular diseases. ${ }^{1-3}$ In addition, normal growth and optimal nutrition should be guaranteed. ${ }^{4}$ Prevention of cardiovascular diseases should start at an early age. ${ }^{5}$ However, current recommendations of the amounts and types of fats suitable for young children vary greatly, both for healthy children and those with diabetes. ${ }^{267}$

Very little is known about the diet of young children with diabetes. We aimed to evaluate how well the diet of young children with diabetes met the dietary recommendations, how the adherence to the recommended diet was maintained during the first two years of diabetes, and whether the diet of these children was nutritionally adequate. In addition, the diet of young children with diabetes was compared with that of healthy children of the same age, sex, and social status.

\section{Subjects and methods}

All the children younger than 6 years of age diagnosed as having IDDM at three university hospitals (Helsinki, Tampere, and Turku) and two district hospitals (Aurora and Jorvi Hospitals in southern Finland) during a 13 month period were invited to enter the study at the time of diagnosis by means of a letter to the parents. Of the 40 families having a newly diagnosed child with IDDM, 39 were willing to participate. The participation rates were $85 \%$ and $83 \%$ at one and two years of duration, respectively. Acceptable dietary data were available from 38 (20 boys, 18 girls) children with diabetes three months after diagnosis, from 37 children six months, from 34 children 12 months, and from 33 children 18 and 24 months after diagnosis. Twelve boys and 12 girls were diagnosed before the age of 4 years. The length of the mother's education was less than 13 years in 16 of 36 children (two missing values), and the length of the father's education was less than 13 years in 22 of 36 (two missing values). Twenty eight of the children were living in urban areas and the remainder (10) were living in rural areas. At the time of diagnosis, 17 of the children were taken care of at home, and 21 were at day care in another family or at a day care centre.

Three months after the diagnosis of diabetes the families were interviewed by one of the authors (SMV) about the kind and amount of food and drink consumed by the child during the two preceding days. Synthetic food models, samples of foods, and dishes of different sizes were used as aides in quantifying portion sizes. At the same visit the parents were given detailed oral and written instructions regarding food recordings. The three day estimated food consumption was recorded during the three days after the visit. Six, 12, 18, and 24 months after the diagnosis, a five day estimated food record was used. The record sheets were sent to the families by mail and reviewed at the clinic or at the child's home by the nutrition investigator (SMV). The recording period consisted of three midweek and two weekend days.

Twelve months after the diagnosis the dietary data of the children with diabetes were compared with those from healthy children. 
Two age and sex matched control children were chosen for each child with diabetes from the files of two well baby clinics in southern Finland, one from an urban community and the other from a rural one. The children with and without diabetes were matched also for the place of residence (rural/urban), and father's and mother's socioeconomic status based on their occupation. ${ }^{8}$ Altogether, 90 control families were asked to participate at the well baby clinic or contacted by a letter, signed by the head nurse of the clinic. Of these 90 families, 77 were willing to participate. ${ }^{9}$ Only those control children whose pair with diabetes gave dietary data 12 months after diagnosis were included in our analyses. Because of a mistake in the handling of the questionnaires, control children were not chosen for one child with diabetes. The final study population comprised 33 diabetic-control pairs (two controls for each child with diabetes). The dietary data from the control children were collected using the three day estimated food record. Food records consisted of two weekdays and one weekend day. After the recording period the investigator (EA-V) met the parents of the control children and the recordings were reviewed. A booklet with pictures of different portions of common foods ${ }^{10}$ was used in checking the estimated amounts of foods. If the child with diabetes or the control child was not taken care of at home, the child's care giver was given written instructions regarding record keeping and separate record sheets. Food records that were filled in at day care outside home were checked by telephone (SMV, EA-V). Similar proportions of children with diabetes and control children attended day care $(65 \%$ of children with diabetes after one year duration $v 54 \%$ of controls). The food consumption data from the children with diabetes were collected throughout the year, whereas those from the control children were collected during May to June. Seasonal differences in food consumption have been very small in Finland since the 1970s. ${ }^{11}{ }^{12}$

Food consumption and nutrient intakes were calculated as means of the five study days for the children with diabetes, and as means of the three study days for control children. The mean values of the data from the two control children matched to each child with diabetes were used. The data were processed using a software system developed for dietary studies. ${ }^{13}$ The food composition data were based mainly on Finnish food composition tables and analytical data obtained from the food industry, and were supplemented by data from foreign food composition tables when no other data were available. All data on the mineral element composition of foods were from the mineral element study, ${ }^{14}$ and on the dietary fibre composition from the Finnish dietary fibre study. ${ }^{15} 16$

The parents' socioeconomic status was determined by their occupation ${ }^{8}$ and length of education. The groups "employers", "own account workers", and "upper level employees" were merged into "upper white collar workers" because of the small numbers of subjects in the two first groups. Of the fathers of
Table 1 Insulin treatment of children diagnosed with diabetes at 0.9-5 years old, at three and 24 months after onset of diabetes

\begin{tabular}{llc}
\hline & $\begin{array}{l}\text { Three months } \\
(n=38)\end{array}$ & $\begin{array}{l}24 \text { months } \\
(n=33)\end{array}$ \\
\hline Number of daily insulin injections & & \\
0 & 2 & 0 \\
1 & 2 & 0 \\
2 & 31 & 23 \\
3 & 1 & 8 \\
4 & 2 & 2 \\
Insulin dose (IU/kg body weight) & 0.5 & 0.7 \\
$\begin{array}{l}\text { Short acting insulin, \% of total } \\
\text { dose (short + intermediate }\end{array}$ & \\
$\quad$ acting insulin) & 20 & 27 \\
\hline
\end{tabular}

the children with diabetes, 16 belonged to upper white collar workers, nine to lower white collar workers, and 13 to blue collar workers. The respective figures among the mothers of the diabetic children were five, 30 , and three. The distribution of parents of control children to the occupational groups was the same as that of the parents of their pairs with diabetes. Differences in food consumption and nutrient intakes were studied between socioeconomic groups defined by father's occupation and the length of parents' education $(<13$ years $v \geqslant 13$ years).

The files of the well baby clinics were used for selecting control children with the permission of the Ministry of Social Affairs and Health. The study protocol was approved by the ethics committees of all the participating hospitals and by the ethics committee of the Public Health Department, City of Helsinki and that of the municipality of Nurmijärvi.

STATISTICAL METHODS

The diets of the children with and without diabetes, as well as the diets of the children with diabetes at the beginning of the study and at the end of the two year follow up, were compared with paired $t$ tests. Abnormally distributed variables were $\log$ transformed in the analyses.

\section{Results}

The number of daily insulin injections, insulin dose/body weight, and the proportion of short acting insulin of total insulin given increased during the two year follow up (table 1).

During follow up the energy adjusted consumption of wheat products and dietary fats and eggs increased, and that of potato and vegetables decreased among children with diabetes (table 2). Compared with the control children, the children with diabetes consumed (for each $4.18 \mathrm{MJ}(1000 \mathrm{kcal})$ ) two to three times more rye products, potato, and vegetables, and a little more margarine (table 2).

Compared with control children, children with diabetes received a greater proportion of energy from cereal products $(30 \% v 22 \%$; $\mathrm{p}<0.001)$, potato and vegetables $(10 \% v 6 \%$; $\mathrm{p}<0.001)$, and a smaller proportion from milk and milk products $(22 \%$ v $25 \%$, respectively; $\mathrm{p}<0.01)$ and beverages, sugar, and similar foods $(3 \% v 8 \% ; \mathrm{p}<0.001)$. The proportion of energy received from fruit and berries $(10 \% v$ $12 \%)$, dietary fats (butter, margarine, and oils) 
Table 2 Mean daily consumption of foods by children diagnosed with diabetes at 0.9-5 years old, three, 12, and 24 months after diagnosis, and that of age, sex, and social status matched control children

\begin{tabular}{|c|c|c|c|c|c|c|}
\hline \multirow[b]{2}{*}{ Food (g/4.18 MF (1000 kcal)) } & \multicolumn{4}{|c|}{ Children with diabetes } & \multirow{2}{*}{$\begin{array}{l}\text { Control } \\
\text { children } \\
(n=66)\end{array}$} & \multirow[b]{2}{*}{$p$ Value * } \\
\hline & $\begin{array}{l}3 \text { months } \\
(n=38)\end{array}$ & $\begin{array}{l}12 \text { months } \\
(n=34)\end{array}$ & $\begin{array}{l}24 \text { months } \\
(n=33)\end{array}$ & $\begin{array}{l}\text { p Value } \\
24 \text { v } 3 \text { months }\end{array}$ & & \\
\hline Cereal products & 96 & 98 & 101 & NS & 76 & $<0.001$ \\
\hline Rye products & 49 & 48 & 45 & NS & 15 & $<0.001$ \\
\hline Wheat products & 30 & 35 & 38 & $<0.01$ & 43 & NS \\
\hline Potato & 92 & 76 & 71 & $<0.01$ & 51 & $<0.001$ \\
\hline Vegetables & 168 & 146 & 120 & $<0.01$ & 68 & $<0.001$ \\
\hline Fruit and berries & 199 & 186 & 177 & NS & 230 & NS \\
\hline Dietary fats & 15 & 17 & 19 & $<0.01$ & 15 & NS \\
\hline Butter & 2 & 3 & 2 & NS & 3 & NS \\
\hline Margarine & 10 & 12 & 13 & NS & 9 & $<0.01$ \\
\hline Oils & 2 & 2 & 2 & NS & 2 & NS \\
\hline Milk and milk products & 419 & 410 & 380 & NS & 364 & NS \\
\hline High fat milk ( $3.9 \%$ fat) & 2 & 1 & 1 & NS & 13 & NS \\
\hline Low fat milk ( $\leqslant 1.9 \%$ fat $)$ & 323 & 307 & 290 & NS & 262 & NS \\
\hline Meat and meat products & 69 & 58 & 62 & NS & 57 & NS \\
\hline Fish and fish products & 10 & 11 & 9 & NS & 9 & NS \\
\hline Eggs & 7 & 8 & 9 & $<0.05$ & 12 & NS \\
\hline Beverages, sugar, and other foods & 100 & 102 & 110 & NS & 83 & NS \\
\hline
\end{tabular}

^Diabetic children 12 months after onset of diabetes compared with control children.

( $11 \%$ in both groups), meat and meat products $(12 \% v 13 \%)$, and fish, fish products, and eggs $(2 \% v 3 \%)$ did not differ between children with diabetes and control children. The most important sources of fat in the diet of both children with diabetes and control children were dietary fats (margarine, butter, and oils) (39\% v 33\% of fat intake; $\mathrm{p}<0.01$ ), milk and milk products $(20 \%$ v $30 \% ; \mathrm{p}<0.001)$, and meat and meat products $(24 \%$ v $23 \%$; not significant).

The proportion of energy derived from protein decreased in the diet of children with diabetes from $20 \%$ at three months to $18 \%$ at 2 years $(p<0.001)$. During the same time period the proportion of energy derived from fat increased from $26 \%$ to $30 \%$ ( $p<0.001$ ), which was accounted for by the increases in saturated (from $9 \%$ to $11 \%$; $<<0.01$ ), monounsaturated (from $9 \%$ to $11 \%$; $<0.01$ ), as well as in polyunsaturated fatty acids (from 6\% to $7 \% ; \mathrm{p}<0.01)$. The proportion of linoleic $(p<0.05)$ and linolenic acid $(p<0.01)$ of energy intake increased from $4.7 \%$ and $0.5 \%$ to $5.3 \%$ and $0.6 \%$, respectively, during the same follow up period. The proportion of carbohydrate of the total energy intake decreased from $54 \%$ at three months to $52 \%$ at two years $(p<0.01)$. The proportion of the energy intake comprising sucrose remained stable during our study, being $3 \%$ both at three months and at 2 years. Compared with control children, the children with diabetes received more energy from protein $(19 \% v 15 \%$; $\mathrm{p}<0.001)$ and carbohydrate $(53 \%$ v 50\%; $\mathrm{p}<0.05)$, and less energy from fat $(28 \% v$ $35 \% ; \mathrm{p}<0.001)$, especially from saturated fatty acids $(11 \%$ v $15 \% ; \mathrm{p}<0.001)$. In addition, the children with diabetes received

Table 3 Mean (SD) daily intake of energy and the intakes of some nutrients for each $4.18 \mathrm{MF}$ (1000 kcal) by children diagnosed with diabetes at 0.9-5 years old, at three, 12, and 24 months after diagnosis

\begin{tabular}{|c|c|c|c|c|}
\hline & $\begin{array}{l}3 \text { months } \\
(n=38)\end{array}$ & $\begin{array}{l}12 \text { months } \\
(n=34)\end{array}$ & $\begin{array}{l}24 \text { months } \\
(n=33)\end{array}$ & $\begin{array}{l}p \text { Value } \\
3 v 24 \text { months } \\
(n=33)\end{array}$ \\
\hline Energy (kcal) & $1341(208)$ & $1472(220)$ & $1536(240)$ & $<0.001$ \\
\hline Energy (MJ) & $5.6(0.9)$ & $6.2(0.9)$ & $6.4(1.0)$ & $<0.001$ \\
\hline Protein $(\mathrm{g})$ & $50(6)$ & $48(6)$ & $45(5)$ & $<0.001$ \\
\hline Fat $(\mathrm{g})$ & $29(5)$ & $31(6)$ & $33(6)$ & $<0.001$ \\
\hline Cholesterol (mg) & $118(24)$ & $128(37)$ & $127(29)$ & NS \\
\hline Carbohydrate (g) & $140(11)$ & $135(12)$ & $134(14)$ & $<0.05$ \\
\hline Total dietary fibre (g) & $16.5(3.3)$ & $15.4(3.4)$ & $14.7(3.7)$ & $<0.01$ \\
\hline WS (g) & $4.1(0.8)$ & $3.7(0.9)$ & $3.5(0.8)$ & $<0.001$ \\
\hline WIS (g) & $12.3(2.7)$ & $11.7(2.6)$ & $11.2(2.9)$ & $<0.05$ \\
\hline Vitamin $A$, ret eq $(\mu \mathrm{g})$ & $911(533)$ & $864(345)$ & $723(381)$ & NS \\
\hline Thiamin (mg) & $1.0(0.2)$ & $1.0(0.1)$ & $0.9(0.1)$ & $<0.01$ \\
\hline Riboflavin (mg) & $1.5(0.3)$ & $1.5(0.2)$ & $1.3(0.3)$ & $<0.001$ \\
\hline Niacin, eq. (mg) & $18.1(2.4)$ & $17.1(2.1)$ & $16.5(2.1)$ & $<0.001$ \\
\hline Vitamin C (mg) & $101(33)$ & $98(39)$ & $78(31)$ & $<0.05$ \\
\hline Vitamin D $(\mu \mathrm{g})$ & $1.5(0.9)$ & $1.7(0.9)$ & $1.8(0.9)$ & NS \\
\hline Calcium (mg) & $781(211)$ & $777(120)$ & $702(190)$ & $<0.01$ \\
\hline Phosphorus (mg) & $1050(140)$ & $1012(113)$ & $950(143)$ & $<0.001$ \\
\hline Potassium (mg) & $2637(393)$ & 2409 (303) & $2240(282)$ & $<0.001$ \\
\hline Magnesium (mg) & $232(26)$ & $219(27)$ & $207(27)$ & $<0.001$ \\
\hline Iron (mg) & $8.7(1.8)$ & $8.1(1.2)$ & $8.5(1.6)$ & NS \\
\hline Zinc (mg) & $8.1(1.0)$ & $7.6(0.9)$ & $7.3(1.0)$ & $<0.001$ \\
\hline Manganese (mg) & $4.0(0.9)$ & $3.9(0.9)$ & $3.9(1.3)$ & NS \\
\hline Copper (mg) & $1.2(0.3)$ & $1.1(0.26)$ & $1.0(0.2)$ & $<0.001$ \\
\hline Selenium $(\mu \mathrm{g})$ & $37(4)$ & $36(4)$ & $35(5)$ & $<0.05$ \\
\hline Molybdenum $(\mu \mathrm{g})$ & $67(12)$ & $66(17)$ & $59(12)$ & $<0.01$ \\
\hline Fluoride $(\mu \mathrm{g})$ & $241(21)$ & $223(23)$ & $213(24)$ & $<0.001$ \\
\hline Chromium $(\mu \mathrm{g})$ & $13(2)$ & $13(3)$ & $13(4)$ & NS \\
\hline Iodine $(\mu \mathrm{g})$ & $171(32)$ & $173(40)$ & $157(31)$ & $<0.05$ \\
\hline
\end{tabular}

WIS, water insoluble non-cellulosic polysaccharides; WS, water soluble non-cellulosic polysaccharides. 
Table 4 Mean (SD) daily intake of energy and intakes of some nutrients by children diagnosed with diabetes at 0.9-5 years old, 12 months after diagnosis, and that of age, sex, and social status matched control children, and recommended dietary allowances

\begin{tabular}{|c|c|c|c|c|c|c|}
\hline & \multicolumn{2}{|c|}{ Children with diabetes } & \multicolumn{2}{|c|}{ Control children } & \multirow[b]{2}{*}{$p$ Value } & \multirow[b]{2}{*}{$\begin{array}{l}\text { Recommended } \\
\text { intake }\end{array}$} \\
\hline & $\begin{array}{l}\text { Boys } \\
(n=17)\end{array}$ & $\begin{array}{l}\text { Girls } \\
(n=16)\end{array}$ & $\begin{array}{l}\text { Boys } \\
(n=34)\end{array}$ & $\begin{array}{l}\text { Girls } \\
(n=32)\end{array}$ & & \\
\hline Energy (kcal) & $1561(202)$ & $1389(172)$ & $1656(297)$ & $1532(221)$ & $<0.01$ & 1170-1980† \\
\hline Energy (MJ) & $6.5(0.8)$ & $5.8(0.7)$ & $6.9(1.2)$ & $6.4(0.9)$ & $<0.01$ & \\
\hline Protein $(\mathrm{g})$ & $75(14)$ & $65(9)$ & $61(15)$ & $57(8)$ & $<0.01$ & $14-26 \ddagger$ \\
\hline Fat (g) & $51(13)$ & $43(9)$ & $65(15)$ & $59(10)$ & $<0.001$ & \\
\hline Cholesterol (mg) & $205(70)$ & $175(57)$ & $250(76)$ & $244(59)$ & $<0.01$ & \\
\hline Carbohydrate (g) & $204(28)$ & $191(25)$ & $211(40)$ & $200(38)$ & NS & \\
\hline Total dietary fibre (g) & $23.4(5.8)$ & $22.2(5.8)$ & $12.7(2.9)$ & $12.1(2.2)$ & $<0.001$ & \\
\hline WS (g) & $5.5(1.1)$ & $5.4(1.6)$ & $3.0(0.7)$ & $3.0(0.7)$ & $<0.001$ & \\
\hline WIS (g) & $17.8(4.7)$ & $16.7(4.2)$ & $9.7(2.3)$ & $9.1(1.6)$ & $<0.001$ & \\
\hline Vitamin A, ret eq $(\mu \mathrm{g})$ & $1313(588)$ & $1238(428)$ & $785(405)$ & $808(339)$ & $<0.001$ & $360-550 \ddagger$ \\
\hline Thiamin (mg) & $1.5(0.2)$ & $1.4(0.2)$ & $1.2(0.3)$ & $1.1(0.2)$ & $<0.001$ & $0.6-1.0 \ddagger$ \\
\hline Riboflavin (mg) & $2.2(0.4)$ & $2.1(0.4)$ & $1.9(0.5)$ & $1.8(0.4)$ & $<0.05$ & $0.7-1.2 \ddagger$ \\
\hline Niacin, eq (mg) & $26(5)$ & $24(3)$ & $23(5)$ & $22(3)$ & $<0.05$ & $8-13 \ddagger$ \\
\hline Vitamin C (mg) & $137(53)$ & $148(48)$ & $98(33)$ & $118(48)$ & $<0.01$ & $36-50 \ddagger$ \\
\hline Vitamin D $(\mu \mathrm{g})$ & $2.8(1.4)$ & $2.2(1.0)$ & $2.3(1.0)$ & $2.7(1.8)$ & NS & $9-11 \ddagger$ \\
\hline Calcium (mg) & $1173(209)$ & $1110(228)$ & $945(283)$ & $940(203)$ & $<0.01$ & $720-880 \ddagger$ \\
\hline Phosphorus (mg) & $1573(264)$ & $1435(206)$ & $1217(299)$ & $1153(178)$ & $<0.001$ & $720-880 \ddagger$ \\
\hline Potassium (mg) & $3516(386)$ & $3520(570)$ & $2682(654)$ & $2619(472)$ & $<0.001$ & \\
\hline Magnesium (mg) & $325(51)$ & $318(50)$ & $232(50)$ & $223(36)$ & $<0.001$ & $72-132 \ddagger$ \\
\hline Iron $(\mathrm{mg})$ & $12(2)$ & $11(2)$ & $11(3)$ & $9(1)$ & $<0.001$ & $9-11 \ddagger$ \\
\hline Zinc (mg) & $11.7(2.0)$ & $10.8(1.6)$ & $9.0(2.1)$ & $8.2(1.1)$ & $<0.001$ & $9-11 \ddagger$ \\
\hline Manganese (mg) & $5.9(1.5)$ & $5.7(1.2)$ & $3.2(0.7)$ & $3.1(0.6)$ & $<0.001$ & $0.9-2.2 \S$ \\
\hline Copper (mg) & $1.7(0.5)$ & $1.6(0.4)$ & $1.0(0.2)$ & $1.1(0.3)$ & $<0.001$ & $0.6-1.7 \S$ \\
\hline Selenium $(\mu \mathrm{g})$ & $57(11)$ & $49(7)$ & $55(14)$ & $50(8)$ & NS & $18-22 \ddagger$ \\
\hline Molybdenum $(\mu \mathrm{g})$ & $96(25)$ & $97(27)$ & $78(15)$ & $76(13)$ & $<0.001$ & $23-835$ \\
\hline Fluoride $(\mu \mathrm{g})$ & $331(44)$ & $316(32)$ & $311(68)$ & $286(39)$ & $<0.05$ & $500-2,800 \Omega$ \\
\hline Chromium $(\mu \mathrm{g})$ & $19(3)$ & $20(6)$ & $20(5)$ & $20(5)$ & NS & $18-1325$ \\
\hline Iodine $(\mu \mathrm{g})$ & $274(83)$ & $231(50)$ & $284(85)$ & $285(82)$ & NS & $63-99 \ddagger$ \\
\hline
\end{tabular}

*Diabetic children versus controls.

†Average energy allowance (National Research Council 1989).

$\ddagger$ Recommended dietary allowance (National Research Council 1989).

¿Estimated safe and adequate daily dietary intake (National Research Council 1989).

WIS, water insoluble non-cellulosic polysaccharides; WS, water soluble non-cellulosic polysaccharides; eq, niacin equivalent; ret eq, retinol equivalent.

less energy from sucrose $(3 \%$ v $16 \%$, $\mathrm{p}<0.001)$.

During the follow up period the nutrient density - that is, the energy adjusted intakes of most vitamins, minerals, and dietary fibre-in the diet of children with diabetes decreased (table 3). The energy intake of both boys and girls with diabetes increased during the time period. The absolute energy intake (table 4) and energy intake/kg body weight were lower for both boys and girls with diabetes than for controls (boys: $0.32 v 0.36 \mathrm{MJ} / \mathrm{kg} ; \mathrm{p}<0.05$; girls: $0.31 v 0.38 \mathrm{MJ} / \mathrm{kg}$; $\mathrm{p}<0.01)$.

Despite the slightly lower energy intake of the children with diabetes, the absolute intakes of most vitamins and minerals studied were greater for these children than for control children (table 4). The dietary fibre intake of children with diabetes was almost two times higher than that of control children. However, the food sources of dietary fibre were similar: children with diabetes received $57 \%$ of dietary fibre from cereal products, $23 \%$ from potato and vegetables, $19 \%$ from fruit and berries, and $1 \%$ from other foods, whereas the respective figures for the control children were $54 \%, 24 \%$, $19 \%$, and $3 \%$.

There were only a few small differences in food consumption and nutrient intake (for each 4.18 MJ) by sex, age, mother's education, place of living, and the day of the week. No differences were detected by father's educational or occupational level. Compared with girls, boys with diabetes consumed more fruit and berries at three months $(p<0.05)$ and their intake of vitamin $C$ was greater $(p<0.05)$.
Control boys received less vitamin $\mathrm{C}$ than girls $(\mathrm{p}<0.05)$. At three months, children with diabetes of mothers with a shorter education ( $<13$ years) compared with those of mothers with a longer education ( $\geqslant 13$ years) consumed more low fat $(1.9 \%$ fat $)$ milk $(\mathrm{p}<0.05)$, and at two years less cereal products $(\mathrm{p}<0.05)$. Children with diabetes living in rural areas compared with those living in urban areas received less vitamin $C(p<0.01)$ and sucrose $(p<0.05)$ and more dietary cholesterol $(\mathrm{p}<0.05)$ at two years. The control children living in rural areas compared with those living in urban areas received less protein from their diet $(p<0.05)$. The differences between week and weekend days were few: during weekdays the control children ate less meat and meat products $(\mathrm{p}<0.05)$ and more cereal products $(\mathrm{p}<0.01)$ and dietary fats $(\mathrm{p}<0.01)$; during weekdays they received more starch $(p<0.05)$ and less sucrose $(\mathrm{p}<0.01)$.

\section{Discussion}

Young Finnish children with diabetes were found to comply remarkably well with the dietary recommendations directed towards children with diabetes. The dietary compliance remained good during the two year follow up. This is the first time that this age group of children with diabetes has undergone a careful dietary survey in Finland and very few studies have been carried out elsewhere. ${ }^{17}$

The study population was representative; all but two children diagnosed as having diabetes at the age of less than 6 years during our study period in the study area participated. These 38 
children with diabetes comprise $35 \%$ of all children younger than 6 years diagnosed to have IDDM during the time period in Finland.

Dietary advice according to Finnish recommendations for subjects with diabetes ${ }^{18}{ }^{19}$ had been given routinely to these children's parents and care givers by the nutritionists and diabetes nurses in the hospitals. Finnish dietary recommendations for subjects with diabetes are in line with recommendations given by European and American authorities. ${ }^{19-22}$ Dietary recommendations for subjects with diabetes and for the general population are essentially the same nowadays. ${ }^{72}$ The only exceptions are the dietary recommendations for young children with diabetes, which differ especially in the amount of fat from those given to young children in general. ${ }^{2367}$

According to UK recommendations, the change to a low fat diet should occur slowly from 2 years of age, so that only after 5 years of age should the fat intake be reduced to $35-40 \%$ of the total energy. ${ }^{2}{ }^{3}$ Recent Nordic nutrition recommendations ${ }^{7}$ for children aged 1 to 3 years recommend a fat intake $30-35 \%$ of total energy, after which the amount recommended for adults $(30 \%)$ could be gradually reached. In our study, the mean proportion of fat of total energy increased slightly with the duration of diabetes, but was always below the UK recommendation. There were no differences in fat intake by age. We found that the intake of energy was slightly lower (approximately $0.418 \mathrm{MJ}$ ) in children with diabetes than in control children. A large Finnish dietary intervention study on reducing cardiovascular risk factors recently showed that a fat intake of $26-29 \%$ of total energy did not affect growth in $7-13$ month old infants. ${ }^{24}$ It is noteworthy that in that study the fat intake was also quite low in the control children, increasing from $29 \%$ of energy at 8 months of age to $33 \%$ of energy at 2 years of age. ${ }^{25}$

In addition to adequacy of energy intake, concern has arisen about intakes of vitamins A and $\mathrm{D}$ by young children with diabetes who follow a diet low in fat. However, because of the lower proportion of fat and sucrose, the diet of children with diabetes contained more of most of the vitamins and minerals studied than that of control children. The children with diabetes favoured fat free and low fat milk products: $20 \%$ of total energy was derived from milk and milk products versus $30 \%$ in the control children, despite similar amounts of milk and milk products consumed. However, vitamin A intake was 1.6 times higher in children with diabetes than in control children. In addition, in control children the mean intake was well above the recommended value. In accordance with earlier Finnish studies on childhood nutrition, ${ }^{26}$ vitamin D intake from food was deficient both among children with diabetes and control children. The most important sources of vitamin $\mathrm{D}$ in the Finnish diet are fortified margarine and fish. High fat milk and skimmed milk contain equal amounts of vitamin $\mathrm{D}$ as a result of enrichment. It is often not possible to reach the recommended vitamin $\mathrm{D}$ intake without dietary supplements, which are recommended for all children in Finland younger than 3 years old. The UK recommendation not to use skimmed milk in children with diabetes aged less than 5 years (to avoid low intakes of vitamins A and D and energy) is not valid for young Finnish children with diabetes.

The quality of dietary fat was in accordance with dietary recommendations in the children with diabetes: during the follow up, intake of saturated fatty acids remained near the recommended upper value of $10 \%$ of total energy, whereas the intake of saturated fatty acids of the control children was excessive. The intake of essential fatty acids was adequate in both groups. $^{7}$

The consumption of potato, vegetables, and rye products was two to three times higher among children with diabetes than control children. Consequently, the intake of dietary fibre was almost two times greater in children with diabetes. No recommendation concerning fibre content of diet has been given for young children with diabetes. For school aged children with diabetes a fibre intake of $20 \mathrm{~g} /$ $4.18 \mathrm{MJ}$ has been recommended. ${ }^{2}$ With their fibre intake of approximately $15 \mathrm{~g} / 4.18 \mathrm{MJ}$, the children with diabetes in our study (aged initially 0.9 to 5 years) were near the recommended value both at the beginning of the study and at the two year follow up.

The dietary compliance in the our study was stricter than has been observed in earlier Finnish studies among adolescents and young adults with diabetes. ${ }^{27}{ }^{28}$ However, the diet of young children with diabetes at the two year follow up was quite near that of adolescents with diabetes aged 11 to 14 years: the proportion of protein intake of total energy was equal $(18 \%)$, that of fat a little lower $(30 \% v$ $32 \%)$, and that of carbohydrate higher $(52 \% v$ $50 \%$ ) in our study, and the fibre density of the diet equal $(15 \mathrm{~g} / 4.18 \mathrm{MJ}) .^{29}$ In Finnish adolescents with diabetes, dietary compliance deteriorated by age and duration of diabetes-for example, the intake of saturated fat increased and that of dietary fibre decreased. ${ }^{28}$

In an American study of children with diabetes aged 4 to 9 years, fairly good dietary compliance was seen. The results concerning intakes of protein, carbohydrate, total and saturated fat, and cholesterol were comparable to our results at two years' follow up. ${ }^{17}$ In that study, the intake of dietary fibre was lower than in Finnish young children with diabetes $(17 \mathrm{~g} /$ day $v 23 \mathrm{~g}$ /day).

The nutritional quality of the diet of young children with diabetes was very good in our study. The only exception was the relatively high intake of protein, which can be detrimental to those children who will develop diabetic nephropathy. ${ }^{30}$ Protein intake could be decreased by increasing the intake of monounsaturated fat or carbohydrates. The intake of sucrose was very low, $3 \%$ of total energy, and it could be increased a little without any deleterious effect on metabolic control, which might increase the social acceptability of the diet. The diet recommended for the child with diabetes would be beneficial also for other 
family members. Similar food choices among family members would decrease the feelings of social isolation of the child with diabetes.

This study was supported by the National Research Council for Agriculture and Forestry, the Academy of Finland, and by the
Finnish Diabetes Research Foundation. We express our Finnish Diabetes Research Foundation. We express our
gratitude to the children and parents who participated in the study.

1 Diabetes Control and Complications Trial Research Group. The absence of a glycemic threshold for the development of long-term complications: the perspective of the diabetes control and complications trial. Diabetes 1996;45:1289-98.

2 Kinmonth A-L, Magrath G, Reckless JPD, the Nutrition Subcommittee of the Professional Advisory Committee of the British Diabetic Association. Dietary recommendations for children and adolescents with diabetes. Diabet Med for children and

3 Magrath G, Hartland BV, the Nutrition Sub-committee of the British Diabetic Association's Professional Advisory
Committee. Dietary recommendations for children and Committee. Dietary recommendations for children and adolescents with diabe
Med 1993;10:874-85.

4 Connell JE, Thomas-Dobersen D. Nutritional management of children and adolescents with insulin-dependen diabetes mellitus: a review by the diabetes care and education dietetic practice group. $\mathcal{F}$ Am Diet Assoc 1991;91:155664.

5 McGill HC. Childhood nutrition and adult cardiovascular disease. Nutr Rev 1997;55:S2-11.

6 American Academy of Pediatrics: Committee on Nutrition. Statement on cholesterol. Pediatrics 1992;90:469-73.

7 Nordic Nutrition Recommendations, original report. Scandinavian fournal of Nutrition 1996;40:161-5.

8 Central Statistical Office of Finland. Classification of socio-economic status. Classification of occupational status. socio-economic status. Classification of occupation

9 Ylönen K, Virtanen SM, Kupiainen E, Räsänen L. Food consumption and nutrient intakes of Finnish children aged one to seven years. Fournal of Human Nutrition and Dietetic 1996;9:207-18.

10 Haapa E, Toponen T, Pietinen P, Räsänen L. Food portion size picture booklet. Helsinki: National Institute of Public Health and Department of Nutrition, University of Helsinki, 1985: 62 .

11 Räsänen L, Niinikangas J. Seasonal differences in food consumption and nutrient intakes. Fournal of the Scientific Agricultural Society of Finland 1977;49:448-55.

12 Hartman AM, Brown CC, Palmgren J, et al. Variability in nutrient and food intakes among older middle-aged men. Implications for design of epidemiologic and validation studies using food recording. Am f Epidemiol 1990;132: 999-1012.

13 Ahlström A, Räsänen L, Kuvaja K. A method of data processing for food-consumption surveys. Ann Acad Sci Fenn $A$ 1972;194:1-8.
14 Koivistoinen P, ed. Mineral element composition of Finnish foods: $\mathrm{Na}, \mathrm{K}, \mathrm{Ca}, \mathrm{Mg}, \mathrm{P}, \mathrm{S}, \mathrm{Fe}, \mathrm{Cu}, \mathrm{Mn}, \mathrm{Zn}, \mathrm{Mo}, \mathrm{Co}, \mathrm{Ni}$,
$\mathrm{Cr}, \mathrm{F}, \mathrm{Se}, \mathrm{Si}, \mathrm{Rb}, \mathrm{Al}, \mathrm{B}, \mathrm{Br}, \mathrm{Hg}, \mathrm{As}, \mathrm{Cd}, \mathrm{Pb}$ and ash. Acta $\mathrm{Cr}, \mathrm{F}, \mathrm{Se}, \mathrm{Si}, \mathrm{Rb}, \mathrm{Al}, \mathrm{B}, \mathrm{Br}, \mathrm{Hg}, \mathrm{As}, \mathrm{Cd}, \mathrm{Pb}$ and ash.
Agricultural Scandinavica $1980 ; \mathbf{3 0}$ (suppl 22):1-141.

Agricultural Scandinavica 1980;30 (suppl 22): 1-141.
Varo P, Laine R, Veijalainen K, Espo A, Wetterhoff A, Koivistoinen P. Dietary fibre and available carbohydrates in Finnish vegetables and fruits. Fournal of the Agricultural Society of Finland 1984;56:49-59.

16 Varo P, Laine R, Veijalainen K, Pero K, Koivistoinen P. Dietary fibre and available carbohydrates in Finnish cereal products. Fournal of the Agricultural Society of Finland 1984; 56:39-48.

17 Randecker GA, Smiciklas-Wright H, McKenzie JM, et al. The dietary intake of children with IDDM. Diabetes Care 1996;19:1370-4.

18 Huttunen JK, Aro A, Pelkonen R, Puomio M, Siltanen I, Akerblom HK. Dietary therapy in diabetes mellitus. Description of a recommendation prepared by the Finnish diabetes association's committee on nutrition therapy. Acta Med Scand 1982;211:469-75.

19 Finnish Diabetes Association. Dietary recommendations for subjects with diabetes [in Finnish]. Diabetes Lääkäriliite subjects with $1988: 1-7$.

20 Diabetes and Nutrition Study Group of the European Association for the Study of Diabetes. Recommendations for the nutritional management of patients with diabetes mellitus. Diabetes Nutr Metab 1988;1:145-9.

21 Diabetes and Nutrition Study Group of the European Association for the Study of Diabetes. Recommendations for the nutritional management of patients with diabetes mellitus. Diabetes Nutr Metab 1995;8:1-4.

22 Franz MJ, Horton ES, Bantle JP, et al. Nutrition principles or the management Diabetes Care 1994;17:490-518.

23 Food and Nutrition Board. Recommended dietary allowances, 10th ed. Washington, DC: National Academy of Sciences, 1989.

24 Lapinleimu H, Viikari J, Jokinen E, et al. The effect of individualized dietary counseling on serum lipoprotein concentrations and growth in 1060 infants aged 7 to 13 months. Lancet 1995;345:471-5.

25 Lagström H, Jokinen E, Seppänen R, et al. Nutrient intakes by young children in a prospective randomized trial of a low-saturated fat, low-cholesterol diet. Arch Pediatr Adolesc Med 1997;151:181-8.

26 Räsänen L, Ahola M, Kara R, Uhari M. Atherosclerosis precursors in Finnish children and adolescents, VII: food consumption and nutrient intakes. Acta Paediatr Scand 1985;318(suppl):135-53.

27 Virtanen SM, Räsänen L, Mäenpää J, Åkerblom HK. Dietary survey of Finnish adolescent diabetics and non-diabetic controls. Acta Paediatr Scand 1987;76:801-8.

28 Virtanen SM, Räsänen L, Tumme R, et al. A follow-up study of the diet of Finnish diabetic adolescents. Acta Paediatr 1992:81:153-7.

29 Virtanen SM, Varo P. Dietary fibre and fibre fractions in the diet of Finnish diabetic and non-diabetic adolescents. Eur 7 Clin Nutr 1988;42:169-75.

30 Pedrini MT, Levey AS, Lau J, Chalmers TC, Wang PH. The effect of dietary protein restriction on the progression of diabetic and non-diabetic renal diseases: a meta-analysis. Ann Intern Med 1996;124:627-32. 